\title{
The Effect of Service-Learning on Trainee Play Therapists and Preschoolers in Connection with Curriculum
}

\author{
Han You Jin, Chung Sun Hee \\ Department of Child Development and Education, Myoungji University, Seoul, Korea \\ 전공교육과 연계한 서비스-러닝이 예비 놀이치료자와 \\ 유아에게 미치는 영향 \\ 한유진, 정선희 \\ 명지대학교 아동학과
}

Objective: Therapists' professional development and improvement of preschoolers' social competence are of critical need, as these are associated with adaptability and future value. A structured educational strategy, to enhance trainee play therapists' academic achievement, provides a safer environment for them to experience what it is like to do fieldwork. Moreover, service receivers have more confidence when community-based needs provided by offering psychological support at an institutional level. As confidence and therapeutic effectiveness are highly correlated, offering psychological support at an institutional level is a reasonable approach. In that, respect both are mutual and reciprocal. Therefore, to activate Service-Learning, this study aims to (1) explore the effect of Service-Learning on the professional development of trainee play therapists, and (2) explore the effect of Service-Learning on the social competence of preschoolers.

Methods: Service-Learning pedagogy in the curriculum-Child-Centered Play Therapy (CCPT) and Play therapy internship class- was applied to investigate the effectiveness of Service-Learning. In addition, the developmental level of trainee play therapists (service provider) and the social competence of preschoolers (service receiver) were measured and analyzed.

Results: Service-Learning pedagogy had a significant effect on both trainee play therapists' development and preschoolers' social competence.

Conclusion: This study found that Service-Learning is a pedagogical method that combines academic learning objectives with community-based needs and priorities, providing an opportunity for higher education institutions to meet these community needs.

Keywords: Service-Learning, trainee play therapist, preschooler, community

\begin{abstract}
서론
유아기는 인지, 언어, 정서의 급격한 발달을 이루며 사회적 관 계가 확대됨에 따라 사회적 능력 또한 발달하는 시기이다. 사

Corresponding Author: Chung Sun Hee, Department of Child Development and Education, Myoungji University, Seoul, Korea, 42-1202, 17, Ogeum-ro 35-gil, Songpa-gu, Seoul, Korea

E-mail: rt.sunny84@gmail.com
\end{abstract}

회적 능력은 유아가 사회의 한 구성원으로 성장하기 위해 반 드시 습득되어야 하는 능력 중 하나로서, 사회적 능력이 잘 발 달한 유아는 다양한 사회적 관계 속에서 더 많은 성장의 기회 를 갖게 된다(Parker \& Asher, 1987). 이러한 다양한 사회적 성

(C)The Korean Association of Child Studies

This is an Open Access article distributed under the terms of the Creative Commons Attribution Non-Commercial License (http:// creativecommons.org/licenses/by-nc/4.0) which permits unrestricted noncommercial use, distribution, and reproduction in any medium, provided the original work is properly cited. 
취감의 경험은 유아가 유능한 인간으로 성장하는데 많은 도 움을 준다(An \& Kim, 2008). 유아시기에 형성된 사회적 능력 은 또래와의 상호작용 및 유치원 환경적응의 정도를 알게 하 며(W. Y. Park \& An, 2005), 이 시기의 사회적 능력의 질은 아 동기의 학교 부적응과 같은 학교생활에서 대인관계 및 사회 적 적응, 그리고 학습적 능력까지도 예측하게 할 뿐 아니라 청 소년기의 이후의 문제행동까지 연결될 가능성이 높다(Waters, Garber, Gornal, \& Vaughn, 1983). 이처럼 유아기는 그 자체로 중 요성을 가지며, 특히 유아시기에 획득해야 하는 사회적 능력은 이후 발달의 적응에 있어 필수적이다. 대부분의 유아는 이러한 발달과정을 자연스럽게 극복해낸다. 하지만 어떤 유아에게는 위협적이고 도전적인 것으로 경험되어 스트레스 요인이 되기 도 한다. 이는 발달 과업을 성취하는데 지장을 주고 환경 적응 을 불리하게 할 뿐 아니라 부적응적인 문제행동으로 연결되어 순조롭게 사회화의 과정을 거치지 못하게 한다. 이에 유아의 부적응 문제를 예방하기 위해 사회적 능력 발달을 돕는 노력이 다각적으로 필요하다(E. S. Shin, Kwon, \& Jeong, 2010).

그러나 유아교육 기관에 입학하는 유아의 $20 \%$ 가 사회적 능 력이 좋지 않으며(Diamon, Hong, \& Barody, 2008), 최근에는 유 아들의 발달 및 적응에 지장을 주는 문제행동이 특정 임상군 이 아닌 일반 아동들에게서도 관찰될 정도로 심각해지고 있어, 이에 관한 연구들이 증가하고 있다(Chi \& Kim, 2014; M. Lee et al., 2013). 또한 유아교육 현장에서 교사들은 유아의 심리적 건 강을 위해 중재 및 치료적 개입의 필요성을 인지하고 있으나, 전문 인력과 제반 시스템의 부족으로 인해 실행이 어렵다고 한 다. 따라서 유아기의 심리적 어려움을 예방하기 위해 교육현 장의 실제적 한계에 대한 분석과 대책 마련이 시급하다(Heo \& Noh, 2012). 이러한 흐름에 따라 아동의 정신건강에 대한 연구 는 더 어린 아동을 대상으로 진행되고 있으며, 가족에서 벗어 나 교육 환경적 변인까지 그 초점이 확대되어 가고 있다(J. H. Lee \& Chung, 2008). 게다가 전언한 대로, 유아기에 나타난 문 제행동을 방치할 경우, 유아기의 심리적 어려움이 만성화되는 경향이 있으며 예후가 좋지 않기 때문에(J. Lee, 2012) 유아의 사회적 능력에 대한 조기개입은 보다 더 전문적이고 체계적으 로 다뤄져 그 위험요소를 줄일 필요가 있다. 또한 이러한 문제 가 이차적 문제로 진행되지 않도록 예방하고 보다 탄력적이고 적응적인 학령기로 진입하도록 도와야 한다.

이러한 접근 중 하나로, 최근에는 유아의 심리·정서적 어려 움을 지원하고 연령에 적합한 사회적 능력을 향상시키기 위해 보육놀이치료를 유아교육 기관에 적용하고 있다(S. Jeong \& Han, 2017; Y. Lee, 2018; Yang \& Han, 2017). 보육놀이치료는
유아교육기관에 놀이치료자들을 파견하여 유아기의 심리적 어려움에 개입하는 반응 서비스(responsive service)로서, 내담 자가 상담실로 찾아가 진행되는 전통적 치료방식에서 벗어나 유아의 생활환경에서 문제행동을 개선시키고자 하는 현장의 필요가 반영된 접근이다(Knitzer, 1993). 따라서 보육놀이치료 는 아동중심 놀이치료를 근간으로 하여, 개별놀이치료를 시행 한다(Ray, 2011). 이는 치료자의 초점이 온전히 유아에게 집중 되는 긴밀한 일대일의 관계를 제공함으로써 유아로 하여금 보 다 더 자유롭게 놀이를 통해 자신을 잘 표현할 수 있도록 촉진 한다(Y. Lee, 2018). 또한 문제행동 경계 선상의 유아들임에도 불구하고 경제적 여건이나 부모의 맞벌이 등으로 인해 치료실 방문이 어려운 유아들을 대상으로 예방적, 자문적, 평가적 모 델로 보육놀이치료를 활용함으로써(Yang \& Han, 2017), 심각 한 수준의 문제 행동유아를 선별하고자 함이다.

한편, 상담 및 심리치료 분야에 대한 높은 관심과 유아, 아 동기의 심리·정서적 건강의 중요성이 주목받으면서 놀이치료 분야가 양적으로 많은 발전을 이루게 되었다. 놀이치료 관련 자격증을 발급하는 기관의 수는 170 개로 증가하였는데(Korea Research Institute for Vocational Education \& Training [KRIVET], 2018), 놀이치료의 수요와 더불어 놀이치료 제공자인 놀이치 료자의 수요 또한 증가했음을 반영한다. 놀이치료는 놀이를 매개로 하여 정서, 행동, 발달적 문제를 경험하고 있는 아동에 게 탁월한 발달적 개입이다. 아동중심 놀이치료는 인간중심 철학을 근거로 모든 개인은 내면에 성장을 향한 본성적 경향 성이 존재하며, 자기와 환경과의 관계 속에서 변화할 수 있는 존재임을 신뢰한다. 따라서 성장을 향한 아동의 적극적이고 선천적인 과정을 촉진하기 위해 치료자는 자기이해를 바탕에 두고 공감, 무조건적 존중, 일치성이라는 치료자의 핵심조건 들을 통합하여 표현함으로써 보다 효과적인 치료적 관계를 맺 고 유지하고자 한다(Ray, 2011). 또한 상담대화기술, 사례이해, 알아차리기, 상담계획, 상담가의 인간적·윤리적 태도와도 같 은 전문적 능력은 오랜 시간 다각적 노력을 통해 발달하기 때 문에, 한 치료자가 숙련된 전문가로 성장하는 발달과정에 대 한 이해가 필요하며, 이는 각 발달 단계별 치료자 교육의 방향 을 설정하는 기준이 된다(Shim, 1998).

Rønnestad와 Skovholt (2003)는 상담자 발달 단계를 6단계로 제시한다. 그중 두 번째 단계인 '초보 학생 단계(the beginning student phase)'는 대학원의 석사과정 시기에 해당한다. 이 단계 에서 학생들은 전공교육에 대한 흥미로움 뿐 아니라 처음으로 실습이라는 강력한 도전을 통해 더욱 내담자를 이해하고 효 과적으로 치료하기위해 끓임없는 배움과 노력을 한다(Baker, 
Daniels, \& Greeley, 1990). 그러나 스스로 개인의 성향, 전문성, 수행 능력 등에 대한 의구심을 느끼며, 높은 수준의 긴장과 불 안, 자신감의 결여를 경험하기도 한다(Yang \& Han, 2017). 따 라서 예비 놀이치료자의 첫 실습경험을 의도적으로 구조화하 여 전공교육과 연계한 보충, 심화교육이 필요하다. 이는 예비 놀이치료자의 발달 수준을 강화해 줄 것이며, 치료자의 세계 관을 형성해 가는 그 시작을 보다 안전한 환경 속에서 경험할 수 있도록 도울 것이다.

1900년대 초, 미국에서 시작된 서비스-러닝(봉사학습)은 '봉사(service)'와 '학습(learning)'이라는 두 개념이 통합된 것으 로서(Chang, 2010; Kwak \& Ahn, 2017), 학생들의 학습경험을 풍부하게 하고, 시민의 책임을 가르치며 지역사회를 강화하기 위해 의미 있는 지역사회 봉사에 자기성찰을 통합하는 학습전 략이다(Havlik, Bialka, \& Schneider, 2016). 서비스-러닝의 주요 한 두 가지 이념은 서비스 제공자와 서비스 수혜자 모두에게 변화와 성장을 제공하는 '상호호혜성(reciprocal)', 그리고 사고 와 행동, 반추적 사고와 실행, 이론과 실천에의 조합으로 이루 지는 경험적 교육으로서의 '교육적 반성(reflection)'(Bae, 2017; Jacoby, 1996)이다. 이러한 이념적 특성을 반영하여 미국의 경 우, 지역사회의 욕구에 반응함과 동시에 예비 상담자를 위한 효과적 학습모형으로 서비스-러닝을 적용한다. 미국의 상담 사 교육 및 감독협회(Association for Counselor Education and Supervision [ACES])에서는 상담사를 교육하는 교육자들이 대 학, 학교, 지역사회 기관 간의 협력 파트너십을 통해 학생들 의 교육을 서비스-러닝과 통합할 것을 권고하고 있다(ACES, 1990). 전공교육과 연계한 상담사 교육에 서비스-러닝을 접 목한 선행연구를 살펴보면, Baggerly (2006)는 대학원 상담수 업에서 지역사회내의 센터와 연계하여 집단 놀이치료를 실 행하였고, Servaty-Seib와 Parikh (2014)는 대학원 상담사 훈련 과정에서 죽음 교육을 통합하기 위해 서비스-러닝을 도입한 바 있다. Burnett, Hamel과 Long (2004)은 상담원의 다문화 역 량을 키우기 위해, Perkins와 Brumfield (2009), Havlik 등(2016) 은 학교 상담교사 훈련을 위해, 그리고 Murray, Lampinen와 Kelly-Soderholm (2006)는 가족체계 이론을 가르치기 위해 대 학원 상담자 훈련 교과과정에 서비스-러닝을 도입하였다. 상 담자 교육에 서비스-러닝을 도입한 결과 예비 상담자의 불안 감이 감소하는 동시에 상담자의 자기효능감이 증가하였으며 (Barbee, Scherer, \& Combs, 2003), 상담현장에서 요구되는 상 담기술개발에 도움을 주고, 상담사라는 직업에 대한 통찰의 기회를 제공하기도 하였다(Alvarado \& Gonzalez, 2012). 또한 서비스-러닝은 학생들이 전공수업시간에 배운 상담기술을 편
안하게 적용하며 내담자에 관한 문제의식을 높이는 데 도움을 주기도 하였다(Arnold \& McMurtery, 2011).

한편, 국내에서는 서비스-러닝이 '봉사학습'과 혼용하여 연 구가 이뤄지고 있다. 봉사학습의 개념과 실천원칙에 관한 연 구(S. Kim, 1997)를 시작으로 현장과의 연계가 중요시되는 교 육학, 사회복지학 등에서 활발한 연구가 진행되고 있으며 $(\mathrm{J}$. Choi, 2011; J.-U. Park, 2015; Seo, 2009), 참여자들의 경험을 탐 색하는 질적 연구(H.-J. Ahn, 2010; A. Choi \& Song, 2015; Son, $\mathrm{Na}, \mathrm{Moon}, \& \mathrm{Seo}, 2011)$, 전공교육과 연계한 서비스-러닝의 모 형개발연구(Han, Park, \& Kim. 2005; Hwang, 2009; Lee \& Kim, 2006; S. M. Shin, 2013; Y.-R.; Won \& Park, 2008;), 교과목으로 서의 서비스-러닝이 갖는 효과성과 운영전략을 탐색한 연구 (Chang, 2010; Bae, 2017)등 연구의 범위가 점점 더 넓어지고 있다. 이와 같이 서비스-러닝은 효과적인 교수-학습전략으로 서 어떠한 학문 분야라도 적용 가능한데 특히 해당 분야가 지 향하는 도움의 가치와 학생들의 학습 성과를 동시에 창출하는 원조 전문(helping profession) 분야의 경우, 더욱 교육적 활용성 이 크다(Won \& Park, 2008). 그래서 원조 전문 분야에서는 교 과과정을 통해 배운 이론적 개념을 현장 경험과 자연스럽게 즉각적으로 적용, 연결, 통합하도록 구조화된 전공교육과 연 계한 서비스-러닝(academic Service-Learning)이 지속해서 꾸준 히 인기를 얻고 있다(Barbee et al, 2003). 특히 놀이치료는 전공 특성상 이론과 실천이 효과적으로 접목될 때 빛을 발하는 실 천적, 경험적 학문이기 때문에 실제적인 연계를 통한 학습이 이뤄지는 교육방법은 더욱 효과적일 것으로 예상된다. 그럼에 도 불구하고 국내의 상담학 및 심리치료 학계에서는 전공연계 서비스-러닝에 관한 연구는 이루어지지 않고 있다. 또한 타 분 야 선행연구의 경우 서비스-러닝의 가장 큰 가치라 볼 수 있는 상호호혜성을 반영하지 못한 채 서비스-러닝의 교육적 효과 만을 검증하여 아쉬움을 남긴다.

이에 본 연구에서는 유아기의 심리, 정서적 어려움 및 사회 적 능력 발달을 지원하는 의미 있는 예방적 치료적 개입에 예 비 놀이치료자 교육을 통합하여 전공연계 놀이치료 서비스러닝의 효과성을 검증하고자 한다. 연구문제는 다음과 같다.

\section{연구문제 1}

전공교육과 연계한 놀이치료 서비스-러닝은 서비스제공자인 예비 놀이치료자의 전문성 발달에 효과가 있는가?

\section{연구문제 2}

전공교육과 연계한 놀이치료 서비스-러닝은 서비스수혜자인 
지역사회 유치원 유아의 사회적 능력 향상에 효과가 있는가?

\section{연구방법}

본 연구에서는 $\mathrm{M}$ 대학교 아동학과의 석사과정 전공수업인 ‘아동중심놀이치료' 와 ‘놀이치료 인턴십’ 과목에 놀이치료 서 비스-러닝을 적용하였고, $\mathrm{M}$ 대학교 아동학과와 $\mathrm{MOU}$ 체결을 맺은 지역사회 내 속한 J 유치원의 유아들을 대상으로 개별 놀 이치료를 하였다. 통제집단을 사용한 사전-사후 검사설계를 활용하여 놀이치료 서비스-러닝의 효과를 분석하였다. 전공 교육과 연계한 놀이치료 서비스-러닝의 효과를 분석하는 연 구모형은 Figure 1과 같다.

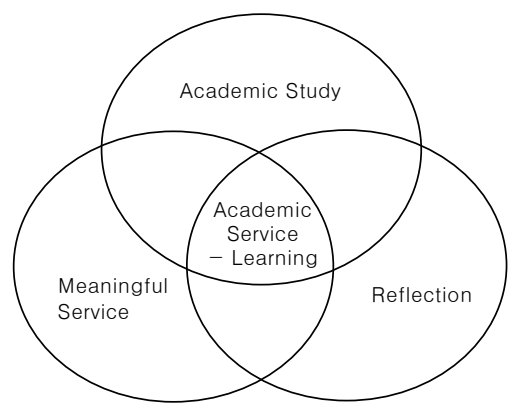

Figure 1. Application model of Service-Learning in play therapy education.

\section{연구대상}

예비 놀이치료자

놀이치료 서비스-러닝에 참여하는 예비놀이치료자들은 총 10 명으로서(실험집단 5명, 통제집단 5명), 사회 인구학적 특성을 간략히 살펴보면 다음과 같다. 모두 미혼의 여성이었으며, 연 령의 평균은 각각 28.6세 $(S D=2.40)$ 와 29.2세 $(S D=1.92)$ 로 석 사 과정 2학기에 재학 중인 학생들이다. 본 프로그램 시작을 기점으로 놀이치료 사례를 시작하는 예비 놀이치료자들로서, 임상 및 슈퍼비전 경험이 전혀 없는 상태였다.

\section{유아}

놀이치료 서비스-러닝에 참여하는 유아는 총 20명으로서(실 험집단 10 명, 통제집단 10 명), 사회 인구학적 특성을 간략하 게 살펴보면 다음과 같다. 유아의 성별은 남아와 여아가 같은
비율로 표집 되었으며, 3세 8명(40\%), 4세 8명(40\%), 5세 4명 (20\%)이었다. 본 연구가 유아교육현장의 사각지대에 놓인 심 리행동 경계선상에 해당하는 유아들의 심리지원서비스라는 것을 명시하는 가정통신문을 각 가정에 전달하였고, 자발적 참여 의사를 밝힌 부모들을 대상으로 놀이치료 서비스-러닝 에 대한 안내 및 교육이 이뤄졌다. 최종 모집된 참여자들은 서 비스를 제공하는 실습생에 관한 내용을 비롯한 본 연구의 목 적과 내용을 충분히 인지하였으며, 연구목적으로 자료가 활용 되는 것에 동의한 자이다. 특히 부모가 맞벌이하고 있지 않아 서 주 양육자가 가정주부인 유아들로 구성하였다. 이는 예비 놀이치료자 훈련에서 부모교육 및 부모상담이 갖는 중요성이 크기 때문에 놀이치료 서비스-러닝의 참여자를 모집하는 과 정에서 의도적으로 구조화하였다. 선별검사를 통한 참여 유아 의 무선배정이 이루어지지 않아 두 집단 간의 동등성에 대한 위협을 갖는다(E. H. Lee, Lee, \& Park, 2006).

\section{코디네이터}

서비스-러닝 모형에는 대학과 지역사회 유치원 간의 조율 및 예비 놀이치료자들을 파견, 지도 감독, 교육하기 위한 코디네 이터를 필요로 하는데, 본 연구에서는 연구자가 놀이치료 준 전문가로서 코디네이터 역할을 이행하였다. 연구자는 박사과 정 5학기 학생이자, 놀이치료 경력 8년 차로 타 학회 놀이치료 1 급 자격증을 소지하고 있다.

\section{연구도구}

\section{상담자 발달수준 척도(Korean Counselor Level Questionnaire [KCLQ])}

예비 놀이치료자의 발달수준을 측정하기 위해 본 연구에서는 Shim (1998)이 개발한 상담자 발달 수준 척도(KCLQ)를 사용하 였다. KCLQ는 상담 장면에서 요구되는 능력에 대한 상담자의 수준을 평가함으로써 상담자의 전문성 발달 수준을 측정하기 위해 개발되었으며, 총 50 문항이다. 상담대화기술 10 문항, 사 례이해 11 문항, 알아차리기 9문항, 상담계획 11 문항, 인간적-윤 리적 태도 9문항으로, 총 5 개 하위영역으로 구성되어있다. 문항 의 채점은 4점 평정척도로 예비 놀이치료자 자기 보고로 이뤄지 며, 높은 점수가 나올수록 발달수준이 높음을 의미한다. Shim (1998)의 연구에서 나타난 신뢰도(Cronbach's $\alpha$ )는 .92이었고, 본 연구 결과 나타난 도구의 신뢰도(Cronbach's $\alpha$ )는 .90이었다. 
유아의 사회적 능력 행동 평가 척도(Social Competence and Behavior Evaluation [SCBE])

지역사회 유치원 내 유아의 사회적 능력을 알아보기 위해 LaFreniere \& Dumas (1995)의 유아의 사회적 능력 행동평가 척도 (SCBE)를 An (2005)이 번안한 척도를 사용하였다. SCBE는 유 아교육 기관에서 일상적으로 일어나는 상황에서 유아의 행동 을 평가하고자 개발되었으며, 교사가 평정하며 총 80 문항이고 5점 평정 척도이다. 친사회적 행동 40 문항, 외적 행동문제 20 문항, 내적 행동문제 20 문항으로, 총 3 개의 하위영역으로 구성 되어있는데 친사회적 행동을 제외한 외적 행동문제와 내적 행 동문제는 모두 역 채점하여 점수를 합산한다. 친사회적 행동 의 높은 점수는 유아가 환경에 적응하고 융통성이 있으며 친사 회적 행동 패턴을 보이는 것을 의미한다. 외적 행동문제의 높 은 점수는 낮은 수준의 문제 행동을 의미하며, 낮은 점수를 받 은 유아들은 자신의 부정적 정서를 또래를 희생시키거나 타인 을 다치게 하는 방법으로 표현하며 문제 발생 시, 자기중심적 또는 사회적으로 잘 받아들여지지 않는 방법으로 해결하려 한 다. 쉽게 울거나 소리 지르며 성인의 권위에 도전하는 경향이 있다. 내적 행동문제는 외적 행동문제와 같이 역 채점하여 점 수를 합산하는데, 내적 행동의 높은 점수 역시 높은 수준의 적 응과 낮은 수준의 문제행동을 의미한다. 낮은 점수를 받은 유 아들은 일반적으로 높은 걱정수준과, 주로 침체되어있으며 성 인에게 의존적 특성을 보인다. 따라서 사회적 상황에서 자신 을 포함하기보다 철회하는 경향이 있어 또래와의 활동에 거의 흥미를 보이지 않는다. 수행이 어렵거나 요구가 거절되었을 경 우에도 성인을 찾고 미성숙한 행동으로 대처하며 포기가 빨 라, 낮은 자아개념을 가진 모습을 보인다. LaFreniere \& Dumas (1995)의 연구에서 나타난 신뢰도(Cronbach's $\alpha$ )는 .86이었고, SCBE를 번안한 An (2005) 연구의 신뢰도(Cronbach's $\alpha$ )는 .78, 본 연구 결과 나타난 도구의 신뢰도는 Cronbach's $\alpha .93$ 이었다.

\section{연구절차}

본 연구는 전공교육과 연계한 놀이치료 서비스-러닝 프로그 램을 개발하고, 그 효과를 검증하고자 시행하였다. 각 연구 단 계별 주요 연구방법은 다음과 같다.

\section{1단계 : 사전조사}

사전 조사는 서비스 프로그램 시작 전인 2016년 11월에 M 대
학교 대학원 아동학과와 $\mathrm{M}$ 대학교 사회교육대학원 아동심리 치료학과 2학기에 재학 중인 예비 놀이치료자 10 명을 대상으 로 자기 보고에 의한 설문지 조사를 하였다. 이 가운데 $\mathrm{M}$ 대학 교 대학원 아동학과 학생 5 명은 실험집단으로, $\mathrm{M}$ 대학교 사회 교육대학원 아동심리치료학과 5명은 본 연구가 종결된 이후 같은 내용의 교육 프로그램을 제공할 것을 약속하고 통제집단 으로 배정하였다. 또한, 동일한 시기에 J 유치원과 C 유치원의 교사의 추천을 받은 유아 중, 부모가 놀이치료 서비스-러닝 참 가에 동의한 아동 20 명을 대상으로 교사보고에 의한 설문지 조사를 실시하였다. 이 가운데 J 유치원의 10 명은 실험집단으 로, C 유치원의 10 명은 통제집단에 포함했다.

\section{2 단계 : 프로그램 구성}

전공교육과 연계한 서비스-러닝 프로그램 운영에 관한 문헌 고찰과 전공 교과 관련 문헌고찰을 근거로 놀이치료 교과목과 서비스-러닝을 연계하는 구체적인 방안에 대해서 지도교수와 코디네이터 간의 논의를 하였다. 놀이치료 서비스-러닝 운영 의 기본방향, 방법, 평가, 운영절차 등을 선정하여 프로그램을 개발하였다.

$$
3 \text { 단계 : 놀이치료 서비스-러닝 프로그램 시행 }
$$

놀이치료 서비스-러닝의 적용은 다음의 Table 1 에 제시한 대로 준 비 및 사전교육, 시행, 평가 및 공유의 단계를 거쳐 진행하였다.

준비단계 프로그램 개발을 위해 국내외의 서비스-러닝 관련 문헌들을 탐색하였으며, 본 연구에서는 서비스-러닝의 개념과 주요 구성요소, 지역사회와의 연관성, 대학에서 전공교육과 연 계한 서비스-러닝 운영 사례와 상담 및 심리치료 영역에서의 운영 사례 등을 고찰하여 상담 및 심리치료 전공과 연계한 서 비스-러닝 프로그램 운영의 기본 방향, 목적, 내용, 평가에 대해 분석하였다. 준비단계는 크게 세 가지로 이뤄졌다. 첫째, 교과 목의 주요 내용을 선정하여 서비스-러닝과 연계 가능하며, 보 충, 심화할 필요성이 있는 내용으로 선정하였다. 서비스-러닝 연계 전공 교과목인 아동중심 놀이치료, 놀이치료 인턴십 수업 과 서비스-러닝이 실제 연결 될 수 있도록 '심리행동 경계 선상 에 있는 유아의 심리적 지원을 통한 예방적 놀이치료' 로 주요 학습 내용을 선정하였다. 또한 예비 놀이치료자의 전문적 발달 을 돕기 위한 사례개념화 교육을 중심으로 아동중심 놀이치료 자의 치료적 관계 형성을 위한 치료적 태도 및 치료기술 적용 
Table 1

Integration Process with Curriculum

\begin{tabular}{|c|c|c|c|}
\hline \multirow[b]{2}{*}{ Step } & \multicolumn{3}{|r|}{ Process of connecting curriculum } \\
\hline & \multicolumn{2}{|c|}{ Curriculum integration process } & Apply \\
\hline \multirow[t]{4}{*}{$\begin{array}{l}\text { Preparations } \\
\text { and pre-training }\end{array}$} & \multirow[t]{2}{*}{ Curriculum } & $\begin{array}{l}\text { Selection of course } \\
\text { main content }\end{array}$ & $\begin{array}{l}\text { Preventive play therapy for preschooler borderline psychological } \\
\text { behavior }\end{array}$ \\
\hline & & $\begin{array}{l}\text { Selection of content } \\
\text { that can be linked to } \\
\text { theory }\end{array}$ & $\begin{array}{l}\text { (1) CCPT therapist's therapeutic attitude } \\
\text { (2) CCPT therapist's therapeutic skills } \\
\text { (3) Case understanding : play evaluation and case conceptualization } \\
\text { (4) Parent counseling skills }\end{array}$ \\
\hline & \multicolumn{2}{|c|}{ Trainee play therapist } & $\begin{array}{l}\text { (1) Guidance and training on Service-Learning } \\
\text { (2) Orientation on structured reflection process (group supervision) }\end{array}$ \\
\hline & \multicolumn{2}{|c|}{ Community organizations } & $\begin{array}{l}\text { (1) Pre-training for Service-Learning for parents } \\
\text { (2) Selecting a play therapy session and participating preschooler } \\
\text { (3) Play therapy room setting }\end{array}$ \\
\hline \multirow{2}{*}{$\begin{array}{l}\text { Execution } \\
\text { (Experiential-Education- } \\
\text { Reflective education ) }\end{array}$} & \multicolumn{2}{|c|}{ Supervision and self-reflection } & $\begin{array}{l}\text { Group supervision progresses every other week } \\
\text { (1) Case conceptualization through play observation, evaluation, parent } \\
\text { counseling and overall understanding of the case } \\
\text { (2) Training in writing journals and case reports }\end{array}$ \\
\hline & \multicolumn{2}{|c|}{ Case study during the class } & $\begin{array}{l}\text { Professor's comments, interaction with colleagues through discussion } \\
\text { sessions }\end{array}$ \\
\hline \multirow[t]{3}{*}{ Evaluation and sharing } & \multicolumn{2}{|c|}{ Service-Learning evaluation } & Service-learning conference (organizational representatives involved) \\
\hline & \multicolumn{2}{|c|}{ Community contribution evaluation } & Evaluate actual contributions through surveys \\
\hline & \multicolumn{2}{|c|}{ Evaluation of the whole class } & $\begin{array}{l}\text { Group discussions among professors, coordinators, and participating } \\
\text { students }\end{array}$ \\
\hline
\end{tabular}

까지 이론부터 실제적인 내용으로 예비 놀이치료자들에게 중 요한 부분을 선별하였다. 둘째, 놀이치료 서비스-러닝이라는 생소한 학습형태에 대한 사전교육이 이뤼졌다. 특히 진행 과 정 중 중요하게 진행 될 집단 슈퍼비전을 통해 서비스-러닝의 이념인 성찰과 반성을 어떻게 경험할지에 대한 안내 및 논의도 이뤄졌다. 마지막으로 이 단계의 중요한 과업으로서, 본 프로 그램의 취지에 적합한 지역사회 내의 유치원을 다음의 기준에 근거하여 $\mathrm{J}$ 유치원으로 최종 선정하였다. 첫째, $\mathrm{M}$ 대학교와 협 력 체결을 맺고, 둘째, 연구목적으로 본 프로그램이 시행되는 것에 동의해야 하며, 마지막으로 $\mathrm{M}$ 대학교와 $5 \mathrm{~km}$ 내에 위치 한 곳이어야 한다. 거리를 하나의 기준으로 선정한 이유는 본 프로그램 이후 서비스수혜 유아가 지속적인 심리적 지원을 받 길 원한다면 학교 내 상담 센터와 연계하여 서비스를 제공하기 위함이다. 그리고 이것이 $\mathrm{M}$ 대학교가 지역 대학으로서 사회적 책임 이행을 한다는 것에 본 연구의 의의가 있기 때문이다. 또 한 본 연구에 참여할 유아 선정, 부모에게 사전 동의 구하기, 유 치원 내 치료실 환경을 마련하는 과정까지 이 단계에서 진행되
었다. 마지막으로 놀이치료 서비스-러닝 시작 전, 본 연구에 참 여하는 유아의 보호자 및 담당교사를 대상으로 사전 교육이 시 행되었다.

시행단계 서비스-러닝 경험과 수업이 동등한 비중으로 구성 되도록 시간 배분을 동일하게 하여 진행하는 것이 효과적이 었다는 선행연구(Han et al., 2005)에 따라 시행단계를 구성하 였다. 교과교육은 본교의 시간표 구성에 따라 주 1 회로 각 3 시 간씩 진행되었고, 연구에 참여한 예비 놀이치료자들은 주 1 회 당 1 시간씩 두 사례를 배정받아 놀이치료 서비스-러닝을 진행 하였다. 격주로 4시간씩 진행된 집단교육 및 슈퍼비전을 통해 코디네이터가 준 슈퍼바이저로서 반성 및 성찰의 시간을 함 께 가졌다. 그룹 슈퍼비전의 초반에는 치료자가 아동을 대상 으로 진행한 놀이관찰, 평가, 부모 상담과 전반적 사례이해를 통한 사례개념화에 관해 집중적 슈퍼비전이 이루졌다. 전공 수업에서 이미 학습한 내용이었지만, 실제 자신의 실습 사례 에 바로 적용해보는 경험은 배운 이론을 바로 적용해보고 더 
심화하여 접근할 수 있는 좋은 경험교육의 요소로 작용하였 다. 슈퍼비전의 중반부에서는 사례가 중기에 접어들면서 사 례개념화에 기반으로 하여 사례를 운영하는 과정과 그 과정 을 기술함에 있어서 셀프 슈퍼비전이 가능하도록 하는 보고 서 작성에 관한 교육이 이뤄졌다. 사례연구보고서를 매주 제 출하고 순환적으로 발표하는 과정은 놀이치료 서비스-러닝 에 대한 반성고찰 및 토론을 가능케 하였다. 후반부로 진행될 수록 준 슈퍼바이저가 일방적으로 전달하는 교육보다는 예비 놀이치료자 동료 간의 토론 및 반성고찰, 피드백이 더욱 가능 하도록 더 큰 비중을 두고 진행하였다. 그룹 내에서 충분히 토 의가 된 사례는 수업시간에 발표함으로써 전공 교수의 지도 와 더 많은 동료 간의 피드백을 통한 더욱 깊은 수준의 성찰과 이해를 이맀다.

평가 및 공유단계 마지막 평가 및 공유단계에서는 예비 놀이 치료자, 지역사회 유치원의 기관장, 교수, 그리고 연구자가 다 함께 참여하여 놀이치료 서비스-러닝의 전반적인 부분과 놀 이치료 서비스-러닝이 지역사회에 기여한 부분, 그리고 전체 과정과 운영에 관해 토의하는 시간을 가졌다.

\section{4단계 : 사후조사}

사후조사는 사전조사와 동일한 질문지를 이용하여 놀이치료 서비스-러닝이 종료된 직후에 실시하였다. 실험집단 예비 놀 이치료자들은 마지막 회기를 마친 직후 사후조사 하였고, 실
험집단 유아들은 마지막 회기 주간에 교사에 의해 사후조사가 진행되었다. 집단별 응답률은 $100 \%$ 이었다.

\section{자료분석}

본 연구에서 수집된 자료 분석은 SPSS 21.0 통계 프로그램을 이용하였다(IBM Co., Armonk, NY). 본 연구의 분석방법은 다 음과 같다. 놀이치료 서비스-러닝 실시 전후에 서비스제공자 인 예비 놀이치료자 발달수준의 변화와 서비스수혜자인 유아 의 사회적 능력의 변화를 살펴보기 위해 비모수 통계방법인 Mann-Whitney U검정과 Wilcoxon 순위합 검정을 하였다.

\section{연구결과}

\section{놀이치료 서비스-러닝이 예비 놀이치료자의 발달수준에 미치는 효과}

\section{사전 동질성 검증}

놀이치료 서비스-러닝의 효과를 검증하기 위해 예비 놀이치 료자의 실험집단과 통제집단의 사전 동질성 검사를 앞서 실시 하였으며 그 결과는 Table 2 와 같다. 예비 놀이치료자의 발달 수준에 대한 하위척도 및 전체척도에서 유의한 차이를 보이지 않았다. 따라서 두 집단은 예비 놀이치료자의 발달수준에 놀 이치료 서비스-러닝이 미치는 효과 검증에 적합한 동질 집단

Table 2

Pre-Homogeneity Test Between Experimental and Control Groups of Trainee Play Therapists

\begin{tabular}{|c|c|c|c|c|c|c|}
\hline \multicolumn{2}{|c|}{ Classification } & \multirow{2}{*}{\multicolumn{2}{|c|}{$\begin{array}{c}\text { Average } \\
\text { rank } \\
6.40\end{array}$}} & \multirow{2}{*}{$\frac{\text { Sum of rank }}{32.00}$} & \multirow{2}{*}{$\begin{array}{c}\text { Mann- } \\
\text { Whitney U } \\
8.00\end{array}$} & \multirow{2}{*}{$\begin{array}{c}z \\
-.99\end{array}$} \\
\hline Counseling skill \& techniques & Experimental group & & & & & \\
\hline & Control group & 5 & 4.60 & 23.00 & & \\
\hline \multirow[t]{2}{*}{ Case understanding } & Experimental group & 5 & 6.40 & 32.00 & 8.00 & -.95 \\
\hline & Control group & 5 & 4.60 & 23.00 & & \\
\hline \multirow[t]{2}{*}{ Awareness } & Experimental group & 5 & 5.60 & 28.00 & 12.00 & -.11 \\
\hline & Control group & 5 & 5.40 & 27.00 & & \\
\hline \multirow[t]{2}{*}{ Counseling plan } & Experimental group & 5 & 5.70 & 28.50 & 11.50 & -.21 \\
\hline & Control group & 5 & 5.30 & 26.50 & & \\
\hline \multirow[t]{2}{*}{ Humanistic attitude } & Experimental group & 5 & 4.80 & 24.00 & 9.00 & -.75 \\
\hline & Control group & 5 & 6.20 & 31.00 & & \\
\hline \multirow[t]{2}{*}{ Total } & Experimental group & 5 & 5.60 & 28.00 & 12.00 & -.11 \\
\hline & Control group & 5 & 5.40 & 27.00 & & \\
\hline
\end{tabular}

Note. $N=10$. 
Table 3

Change in Development Levels of Trainee Play Therapists

\begin{tabular}{|c|c|c|c|c|c|c|c|c|c|c|c|}
\hline & & \multicolumn{2}{|c|}{ Pre-test / Post-test } & \multicolumn{3}{|c|}{ Negative rank } & \multicolumn{3}{|c|}{ Positive rank } & Ties & \multirow[b]{2}{*}{$z$} \\
\hline \multicolumn{2}{|c|}{ Classification } & $M(S D)$ & $M(S D)$ & $n$ & $\begin{array}{c}\text { Aver-age } \\
\text { rank }\end{array}$ & $\begin{array}{c}\text { Sum of } \\
\text { rank }\end{array}$ & $n$ & $\begin{array}{l}\text { Aver-age } \\
\text { rank }\end{array}$ & $\begin{array}{c}\text { Sum of } \\
\text { rank }\end{array}$ & $n$ & \\
\hline $\begin{array}{l}\text { Counseling skill } \\
\& \text { techniques }\end{array}$ & Control group & $20.00(1.22)$ & $21.00(1.00)$ & 0 & 0.00 & 0.00 & 4 & 2.50 & 10.00 & & -1.89 \\
\hline $\begin{array}{l}\text { Case } \\
\text { Understanding }\end{array}$ & Experimental group & $22.40(3.64)$ & $34.20(3.19)$ & 0 & 0.00 & 0.00 & 5 & 3.00 & 15.00 & & $-2.03^{*}$ \\
\hline Awareness & Control group & $19.40(2.07)$ & $20.20(0.84)$ & 1 & 4.00 & 4.00 & 4 & 2.75 & 11.00 & & -0.97 \\
\hline \multirow{2}{*}{ Counseling plan } & Experimental group & $21.00(5.52)$ & $26.00(1.22)$ & 1 & 1.00 & 1.00 & 4 & 3.50 & 14.00 & & -1.76 \\
\hline & Control group & $21.00(3.60)$ & $21.00(2.92)$ & 1 & 3.00 & 3.00 & 2 & 1.50 & 3.00 & 2 & 0.00 \\
\hline $\begin{array}{l}\text { Humanistic } \\
\text { attitude }\end{array}$ & Experimental group & $23.00(0.70)$ & $35.00(1.58)$ & 0 & 0.00 & 0.00 & 5 & 3.00 & 15.00 & & $-2.03^{*}$ \\
\hline
\end{tabular}

Note. $N=10$.

${ }^{*} p<.05$.

으로 확인되었다.

놀이치료 서비스-러닝 사전·사후 실험집단과 통 제집단 간의 예비 놀이치료자의 발달수준 비교

예비 놀이치료자들의 발달수준 변화를 살펴보면, 놀이치료 서 비스-러닝 실시 이후 예비 놀이치료자의 발달수준이 유의하게 증가한 것으로 나타났으며 $(z=-2.02, p<.05)$, 이는 놀이치료 서 비스-러닝을 통해 예비 놀이치료자가 놀이치료자로서의 역할 수행에 도움이 되었음을 의미한다(Table 3). 하위영역별로 살펴 보면, 상담계획 $(z=-1.76)$ 을 제외하고 상담대화기술 $(z=-2.03$, $p<0.05)$, 사례이해 $(z=-2.03, p<0.05)$, 알아차리기 $(z=-2.03, p$ $<0.05)$, 인간적·윤리적 태도 $(z=-2.03, p<0.05)$ 영역에서 전체 적으로 유의하게 증가하였다. 이는 놀이치료 서비스-러닝을 통 해 교과 이론수업에서 습득한 지식을 실제 임상현장에서 적용 해 봄으로써 놀이치료자로서의 전문적, 인간적 태도를 습득하 고 더 나아가 놀이치료자로서 성장했음을 알 수 있다.

\section{유아의 사회적 능력의 변화}

\section{사전 동질성 검증}

놀이치료 서비스-러닝의 효과를 검증하기 위해 유아의 실험
집단과 통제집단의 사전 동질성 검사를 앞서 실시하였으며 그 결과는 Table 4 와 같다. 유아의 사회적 능력에 대한 하위척도 및 전체 척도에서 유의한 차이를 보이지 않았다. 따라서 두 집 단은 유아의 사회적 능력에 놀이치료 서비스-러닝이 미치는 효과 검증에 적합한 동질 집단으로 확인되었다.

\section{놀이치료 서비스-러닝 사전·사후 실험집단과 통제집단 간 유아의 사회적 능력 비교}

유아의 사회적 능력의 변화를 살펴보면, 놀이치료 서비스-러 닝 실시 이후 유아의 사회적 능력이 유의하게 증가한 것으로 나타났으며 $(z=-2.29, p<.05)$, 이는 놀이치료 서비스-러닝을 통해 예비 놀이치료자가 놀이치료자로서의 역할을 수행하는 데 도움이 되었음을 의미한다(Table 5). 하위영역인 친사회적 행동 $(z=-2.25, p<0.05)$ 과 외적 행동 $(z=-2.67, p<0.01)$ 에서도 유의한 차이가 있는 것으로 나타났다. 놀이치료 서비스-러닝 실시 후 유아들의 외적 행동 영역이 현저하게 증가함을 보여 주었는데, 이는 놀이치료를 통해 유아들의 분노, 공격성과 같 은 부정적 정서가 해소되었고, 자기중심성 및 적대감이 감소 하였음을 알 수 있다. 또한 친사회성 영역에서도 유의미한 차 이를 보여주고 있어 놀이치료 서비스-러닝을 통해 유아들이 환경에 적응하고 융통성을 보이는 등, 친사회적 행동 패턴이 증가하게 된 것으로 설명할 수 있다. 
Table 4

Pre-Homogeneity Test Between the Experimental Group and Control Group of Preschoolers' Social Competence

\begin{tabular}{|c|c|c|c|c|c|c|}
\hline \multicolumn{2}{|c|}{ Classification } & \multirow{2}{*}{$\begin{array}{c}n \\
10\end{array}$} & \multirow{2}{*}{$\begin{array}{c}\text { Average rank } \\
10.35\end{array}$} & \multirow{2}{*}{$\begin{array}{c}\text { Sum of rank } \\
103.50\end{array}$} & \multirow{2}{*}{$\begin{array}{c}\text { Mann-Whitney U } \\
48.50\end{array}$} & \multirow{2}{*}{$\begin{array}{c}z \\
-.11\end{array}$} \\
\hline Prosocial Behavior & Experimental group & & & & & \\
\hline & Control group & 10 & 10.65 & 106.50 & & \\
\hline \multirow[t]{2}{*}{ Externalizing Problem } & Experimental group & 10 & 9.75 & 97.50 & 42.50 & -.57 \\
\hline & Control group & 10 & 11.25 & 112.50 & & \\
\hline \multirow[t]{2}{*}{ Internalizing Problem } & Experimental group & 10 & 9.85 & 98.50 & 43.50 & -.49 \\
\hline & Control group & 10 & 11.15 & 111.50 & & \\
\hline \multirow[t]{2}{*}{ Total } & Experimental group & 10 & 9.80 & 98.00 & 43.00 & -.53 \\
\hline & Control group & 10 & 11.20 & 112.00 & & \\
\hline
\end{tabular}

Note. $N=20$.

Table 5

Change in Preschoolers' Social Competence

\begin{tabular}{|c|c|c|c|c|c|c|c|c|c|c|c|}
\hline \multirow{2}{*}{\multicolumn{2}{|c|}{ Classification }} & \multicolumn{2}{|c|}{ Pre-test / Post-test } & \multicolumn{3}{|c|}{ Negative rank } & \multicolumn{3}{|c|}{ Positive rank } & \multirow{2}{*}{$\begin{array}{c}\text { Ties } \\
n\end{array}$} & \multirow[b]{2}{*}{$z$} \\
\hline & & $M(S D)$ & $M(S D)$ & $n$ & $\begin{array}{c}\text { Aver-age } \\
\text { rank }\end{array}$ & $\begin{array}{c}\text { Sum of } \\
\text { rank }\end{array}$ & $n$ & $\begin{array}{l}\text { Aver-age } \\
\text { rank }\end{array}$ & $\begin{array}{c}\text { Sum of } \\
\text { rank }\end{array}$ & & \\
\hline \multirow{2}{*}{$\begin{array}{l}\text { Prosocial } \\
\text { Behavior }\end{array}$} & Experimental group & $99.20(11.47)$ & $108.70(12.32)$ & 1 & 5.50 & 5.50 & 9 & 5.50 & 49.50 & & $-2.25^{*}$ \\
\hline & Control group & $97.70(7.15)$ & $98.90(5.78)$ & 5 & 4.50 & 22.50 & 5 & 6.50 & 32.50 & & -0.51 \\
\hline \multirow{2}{*}{$\begin{array}{l}\text { Externalizing } \\
\text { Problem }\end{array}$} & Experimental group & $39.30(11.80)$ & $52.20(12.13)$ & 0 & 0.00 & 0.00 & 9 & 5.00 & 45.00 & 1 & $-2.67^{* *}$ \\
\hline & Control group & $39.60(5.95)$ & $40.80(5.41)$ & 4 & 3.63 & 14.50 & 5 & 6.10 & 30.50 & 1 & -0.95 \\
\hline \multirow{2}{*}{$\begin{array}{l}\text { Internalizing } \\
\text { Problem }\end{array}$} & Experimental group & $51.50(11.96)$ & $57.70(8.80)$ & 1 & 7.00 & 7.00 & 8 & 4.75 & 38.00 & 1 & -1.84 \\
\hline & Control group & $51.90(5.80)$ & $50.90(5.70)$ & 6 & 4.50 & 27.00 & 3 & 6.00 & 18.00 & 1 & -0.53 \\
\hline \multirow[t]{2}{*}{ Total } & Experimental group & $63.33(10.33)$ & $72.87(8.71)$ & 2 & 2.50 & 5.00 & 8 & 6.25 & 50.00 & & $-2.29^{*}$ \\
\hline & Control group & $63.06(15.28)$ & $63.53(10.89)$ & 3 & 5.67 & 17.00 & 6 & 4.67 & 28.00 & 1 & -0.65 \\
\hline
\end{tabular}

Note. $N=20$.

${ }^{*} p<.05 .{ }^{* *} p<.01$.

\section{논의 및 결론}

본 연구는 지역사회에 기반을 둔 놀이치료 서비스-러닝의 활 성화를 위한 기초연구이다. 예비 놀이치료자 교육으로서 놀이 치료 서비스-러닝의 효과성 및 놀이치료 서비스-러닝을 통해 지역사회의 욕구를 해결하는 대학의 사회적 책임이행의 가능 성을 검토하고자 수행되었다. 놀이치료 서비스-러닝이 서비 스 제공자인 예비 놀이치료자의 치료자 발달수준과 서비스 수 혜자인 유아의 사회적 능력 수준에 미치는 영향을 분석하였으 며, 그 결과를 중심으로 아래와 같은 결론을 내릴 수 있다.

첫째, 전공교육과 연계한 놀이치료 서비스-러닝은 예비 놀 이치료자의 발달수준 변화에 긍정적인 효과가 있었다. 하위영 역별로 살펴보면 상담대화기술, 사례이해, 알아차리기, 인간 적·윤리적 태도의 영역에서 변화를 보였다. 이는 전공교육에 서 습득한 기술을 실제 치료과정에 바로 적용해 볼 수 있는 놀
이치료 서비스-러닝의 특화점이 유효했다고 본다. 예비놀이 치료자들은 유아의 핵심 문제를 이론에 근거해서 파악해 볼 수 있었으며, 여러 가설을 또다시 이론에 근거해서 확인하는 과정을 거쳐 보다 깊은 사례이해를 바탕으로 효과적인 사례 운영을 가능케 했을 것이다. 따라서 전공교육, 집단 슈퍼비전, 임상 경험, 자기성찰이 순환적으로 이루어진 놀이치료 서비 스-러닝은 예비 놀이치료자들의 놀이치료에 대한 전문적 능 력 발달뿐 아니라 내담아동을 한 인간으로서 존중하고, 수용 하는 치료자의 인간적, 윤리적 성장도 도왔으며, 이를 통해 치 료자로서 좀 더 성장 할 수 있었다. 놀이치료자의 전문성은 전 문적, 구체적인 교육과 훈련을 통해 발달하는 능력이며, 전문 적 능력은 놀이치료의 교육, 실습, 훈련의 과정과 직결된다는 연구(Z. Kim, Han, \& Lee, 2009; Moras \& Strupp, 1982)와도 의 견을 같이한다. 특히 단기간의 훈련만으로는 예비 놀이치료 자들이 습득하기 어려운 사례이해 영역에서도 긍정적인 영향 
을 끼쳤는데, 이는 예비 놀이치료자를 대상으로 한 보육놀이 치료 인턴십 모델 효과성 연구(Yang \& Han 2017)와는 다른 결 과이다. 두 연구 모두 예비 놀이치료자의 전문성을 발달시키 기 위한 훈련과정으로 보육놀이치료를 실시하였으나, 치료자 교육의 주 초점이 달랐다는 점에서 서로 다른 결과가 나온 것 으로 예측된다. 보육놀이치료 인턴십의 교육 프로그램은 치 료자가 내담자와의 치료적 관계의 의사소통을 촉진할 수 있는 치료적 기법을 익히고 반응 연습을 하는 것에 초점이 맞춰져 있다(Yang \& Han, 2017). 반면, 본 연구의 예비 놀이치료자 교 육 프로그램은 예비 놀이치료자의 교육 요구에 관한 선행연구 (K. Kim \& Moon, 2000; M. Kim, 2009; Jee, Park, \& Lim, 2005) 와 초심 상담자들이 겪는 어려움에 관한 연구(G. Kim \& Jeong, 2004; Rønnestad \& Skovholt, 2003)를 바탕으로 예비 놀이치료 자의 발달단계를 고려하여 사례개념화 교육에 더욱 초점을 두 었다. 이는 예비놀이치료자가 내담자의 어려움과 문제의 기 저에 있는 심리적 역동과 행동을 이해하는 사례개념화에 관 한 지식을 선행학습하고, 내담아동과 치료적 관계를 맺는 것 에 관한 훈련을 차후에 시행한다면 더욱 효과적일 것으로 예 상했기 때문이다. 이는 초심 상담자를 대상으로 진행한 사례 개념화 교육이 전문적 능력 발달에 효과적이었다는 선행연구 (M. Lee \& Yeon, 2004; M. Lee, 2013)와 맥락을 같이한다. 한편, 치료계획영역에서는 유의미한 효과가 나타나지 않았는데, 치 료계획은 내담유아의 문제와 증상에 가장 적절한 기법을 선택 하고, 그 기법의 특성에 맞게 계획을 세우는 과정이다. 본 연구 는 전공교육과 연계한 놀이치료 서비스-러닝으로서 '아동중 심놀이치료' 교과 내용에 충실히 하고자 하였다. 아동중심 놀 이치료에서 놀이치료자는 아동을 성장 지향적 존재로서 보고 문제나 증상으로 평가하지 않기 때문에 아동의 행동이나 대 화를 지시하지 않고 아동을 따르며, 치료자가 판단한 긍정적 인 행동을 강화하지 않는다. 즉, 아동중심 놀이치료는 어떠한 치료적 기법보다도 치료적 관계에 초점을 두고 진행된다(Ray, 2011). 그러나 간혹 이러한 철학적 부분이 아동중심 놀이치료 는 훈련 없이 마음만 있으면 가능한 것으로 가볍게 여겨지거 나, 모든 것을 아동이 진행하고 치료자는 아무것도 해서는 안 되는 존재처럼 치료자의 역할을 축소시켜 이해하기도 한다 (Chung, Jae, Lee, Shin, \& Park, 2016). 이처럼 예비 놀이치료자 의 발달수준 상, 아동중심 놀이치료의 철학과 상반되는 것처 럼 보이는 상담계획영역을 깊이 있게 이해하고, 통합적으로 계획과 전략을 효과적으로 다루는 데 한계를 경험하는 것으 로 예측된다. 이는 Yang과 Han (2017)의 연구 결과와 같다. 한 편, 초심 상담자를 대상으로 사례개념화 집단 교육을 한 연구
(M. Lee, 2013)에서는 사례계획영역에서도 유의미한 결과가 나왔는데 집단교육에 참여한 연구대상자들이 3 년의 상담경력 이 있는 초심 상담자라는 점을 생각해본다면, 상담계획영역은 예비상담자 수준의 치료자가 체득하기에는 무리가 될 수 있으 며, 따라서 초심 놀이치료자와 별개로 예비놀이치료자에 관한 정의가 필요하고, 세분화된 발달단계에 적합한 교육에 관한 연구 또한 더욱 활발히 이뤄져야 할 것이다.

둘째, 전공교육과 연계한 놀이치료 서비스-러닝은 서비스 수혜 유아의 사회적 능력 성장과 발달에 높은 효과성을 보였 다. 개별적으로 진행된 놀이치료에서 아동을 온전히 이해하 고자 하는 치료자의 집중된 태도는 존재로서 존중받는 관계를 경험하게 하였고, 이러한 온전한 수용과 공감의 경험은 또래 관계를 포함한 대인관계에 긍정적 영향을 주어 긍정적 사회적 행동을 하는 데 도움을 주었음을 알 수 있다. 또한, 정서적 탄 력성이 떨어지면 외현적 문제행동이 많이 일어나고(Y. S. Lee, 2014), 자기통제능력은 유아의 공격 행동에 직접적 영향을 미 치는데(Koo, 2009), 놀이치료실에서 유아들은 자신이 선택하 고 그 선택에 대해 책임지는, 즉 자신의 감정과 행동을 조절하 는 경험은 사회적으로 용인받는 범위 내에서 자신을 건강하게 표현하는 데 도움을 주었을 것으로 예상된다. 이는 보육놀이 치료가 유아들의 부정적 감정 해소 및 긍정적 관계 경험을 통 해 또래 관계 증진 및 사회성 발달에 효과적이라는 선행연구 (Yang \& Han, 2017)와도 일치하는 결과이다. 한편, 아동의 내 적 행동에는 유의미한 효과가 나타나지 않았다. 본 연구에서 유아의 사회적 능력의 효과성 검증은 교사 보고로 이뤼졌는 데, 대부분의 유치원 교사는 유아의 정서·사회적 문제행동을 진단, 평가, 중재하는데 관한 적절한 훈련을 받지 못한 경우가 많고, 교사들의 스트레스 요인이자 수업의 방해요인이 되는 아동의 외현화 문제행동에 비해 유아의 보고로 인식되는 내재 화 문제행동은 그 증상을 파악하거나 심각성을 인지하는 것 이 어렵다(Y. Kim, 2007; Melissa, Jessica, \& Gretchen, 2017). 게 다가 본 연구에 참여한 유아들은 정서-행동 상 임상 수준의 어 려움을 호소하는 것이 아니었으므로 내담 유아의 내적행동과 그 변화에 대해서 교사가 민감하게 알아차리기에 더욱 어려웠 을 것으로 예측된다. 또한 유아의 경우는 가족 환경적 맥락, 그 중에서도 주 양육자인 어머니의 개인내적 특성에 가장 많은 영향을 받는다는 선행연구(Hong, 2015; J. Kim \& Sung, 2014; Wang \& Han, 2011)를 통해 유아의 주 양육자인 어머니의 심 리적 건강의 중요성이 미치는 영향이 클 것으로 예상한다. 그 러나 본 연구는 어머니의 양육 태도, 심리적 건강성과 같은 개 인 변인과 유아의 사회적 능력 간의 상호작용을 직접 관찰하 
여 비교한 결과가 아니기 때문에 유아의 내적 행동에 부모의 개인 변인이 미치는 부정적 영향을 예측할 수 없음에 아쉬움 을 남긴다.

본 연구의 의의를 요약하면 다음과 같다. 첫째, 본 연구는 놀이치료 서비스-러닝의 개념을 명시하였다. 놀이치료 서비 스-러닝은 대학이 지역사회 유치원의 요구를 반영하여 예비 놀이치료자를 배정하고, 놀이치료 과정을 대학 입장에서 지 도, 관리하는 점을 특징으로 한다. 이러한 특징은 예비 놀이치 료자들이 실습기관을 선정해야 하는 부담을 줄여 줄 뿐 아니 라, 치료 과정에 대한 지도가 필요한 발달단계에 있는 예비 놀 이치료자들에게 놀이치료 서비스-러닝을 대학에서 제공함으 로써 안정된 환경에서 놀이치료 실습의 교육적 의의를 더욱 강화하여 실시할 수 있다. 또한 지역사회 입장에서도 한 개인 이 주체가 되어 진행하는 프로그램이 아닌 대학 차원에서 지 역사회에 제도적으로 접근함으로써 '예비 놀이치료자'에 대한 심리적 거부감을 낮추고 치료과정에 보다 더 신뢰감을 느끼고 참여하게 한다.

둘째, 의도적으로 구조화한 서비스-러닝을 통해 경험 교육 의 한계를 보완할 수 있었다. 경험교육으로서의 서비스-러닝 은 전공수업에서 배운 이론적 지식을 지역사회에서의 학습으 로 연장하는 과정으로 전공교육, 의미 있는 봉사경험, 자기 성 찰의 시간이 구조적으로 설정되어 있어 학습과 발달이 동시에 일어나도록 돕는다. 그러나 예비 놀이치료자에게 모든 경험 이 긍정적으로 전문성 발전에 도움이 된다고 볼 수 없으며, 통 찰능력이 숙련된 놀이치료자보다 부족하여 놀이치료 서비스러닝의 자기성찰 과정 또한 교육적 접근이 필요하다고 생각된 다. 이처럼 예비 놀이치료자의 사례 경험은 전문성 발달의 시 작점에서 갖는 의미가 크고, 그 자체로 갖는 중요성이 있기에 의도적으로 구조화하여 교육하는 것이 중요하다. 따라서 놀이 치료 서비스-러닝은 전공교육 과정에서 높은 중요도에 비해 교과과정 상 충분히 다루지 못하고 지나쳤던 부분들을 보충 하고 심화하는 교육과정으로 운영함으로써 예비 놀이치료자 가 임상현장에서 실제적으로 경험하는 어려움을 반영하여 경 험 교육의 내용을 구조화하였다. 또한 초심 상담자들은 지도 감독자의 평가에 대한 걱정과 긍정적 지지를 해 줄 수 있는 멘 토가 부족함을 호소하는데(Rønnestad \& Skovholt, 2003), 놀이 치료 서비스-러닝은 코디네이터가 예비 놀이치료자들과 협력 적 관계를 맺고, 정서적으로 지지자 역할을 감당하며 그들의 심리. 발달수준에 적합한 건설적 피드백을 제공함으로써 치료 자로서 성장해가는 개별화 과정을 함께 하였다. 이는 첫 사례 경험에서 일어나는 불안하고 복잡한 여러 상황을 성장의 기회
로 활용할 수 있도록 하였고 전문성 발달에 필요하고도 중요 한 에너지로 사용되었다.

셋째, 지역사회 유치원에서의 유아들을 위한 심리지원 서 비스를 제공하여 발달상 이후에 나타날 수 있는 정서·행동 상 의 문제를 예방하였다. 이는 유아교육현장에서 예방적 중재가 중요하고 실제적 개입을 필요로 하나, 현실적으로 이행이 어 려운 상황 의 간격을 좁히는 실제적인 방안이 되었다는 점에 서 의의가 있다.

본 연구의 결과를 토대로 후속 연구를 위해 다음과 같이 제 언하고자 한다.

첫째, 예비 놀이치료자의 발달수준이 치료자 자기 보고로 만 평가되었기 때문에 객관적 평가로 보기엔 무리가 있을 수 있다. 따라서 추후 연구에서는 예비 놀이치료자의 치료 과정 과 슈퍼비전 수행에 대해 슈퍼바이저의 평가가 동시에 이뤄진 다면 보다 객관적이고 명확하게 치료자 발달수준의 변화를 파 악할 수 있을 것이다.

둘째, 본 연구에서는 대학과 지역사회 간의 협력을 중시하 면서도 유아의 사회적 능력을 교사의 보고로만 평가했으며, 지역사회의 유아교육 기관에서 실시했음에도 협력적 체계가 미약했다는 한계점을 갖는다. 따라서 추후 연구에서는 유아의 사회적 능력 향상을 위해 담임교사, 치료사, 주 양육자의 미시 체계로 형성된 기능적인 중간체계를 활용한 서비스 연계 체계 를 강화한다면 유아의 심리, 정서적 부적응의 발달을 효과적 으로 돕고, 평가할 수 있을 것이며 더 나아가 지역사회에 기반 을 둔 서비스-러닝의 의미를 더욱 강화할 수 있을 것이다.

셋째, 본 연구의 참여자인 유아를 선별할 때, 실험설계의 절 차를 철저히 따르지 못하고 부모의 요구와 교사의 추천으로만 이뤄졌다는 한계점을 갖는다. 따라서 차후의 연구에서는 측정 도구를 통해 유아의 사회적 능력의 수준을 정확하게 평가한다 면, 유아의 상태에 따라 예방, 조기개입, 치료적 차원의 구체적 이고 정확한 중재가 이뤄질 수 있을 것이다.

넷째, 예비 놀이치료자들이 동일한 전공교육과 서비스-러닝 교육을 받았더라도, 모든 예비 놀이치료자가 실제 치료과정에 서 같은 처치를 했다고 보기엔 무리가 있다. 따라서 추후 연구 에서는 놀이치료 서비스-러닝에 참여한 예비 놀이치료자들의 경험에 관한 질적 연구 또는 적은 수의 사례를 심층적으로 분 석하는 사례연구가 시행된다면 놀이치료 서비스-러닝이 갖는 의미와 시사점을 보다 더 구체적으로 명시할 수 있을 것이다.

다섯째, 유아의 심리 사회적 능력은 주 양육자의 심리적 건 강 및 기질과 같은 개인내적 요인이 중요하게 작용한다. 따라 서 추후연구에서는 박사과정 학생의 서비스-러닝으로서 부모 
상담 또는 부모교육이 동시에 진행된다면 지역사회의 요구를 더욱 충족할 뿐 아니라, 더욱 다양한 교과목과 많은 대상에 서 비스-러닝을 효과적으로 적용할 수 있을 것이다.

여섯째, 놀이치료 서비스-러닝이 학과 차원이 아닌 대학 내 에 제도적으로 정착하기 위한 서비스-러닝의 제도화 연구가 필요하다. 서비스-러닝이 실습의 보조 장치 수준으로 이해 및 활용되지 않도록 구조적으로 교육, 연구, 봉사 간의 통합을 이 룰 수 있는 대학-지역협력모델 개발 연구가 이뤄진다면 전공 을 통한 대학의 사회적 책임 이행이 더욱 능동적으로 가능할 것이다. 또한, 제도화 과정에서 코디네이터의 개념 및 역할이 보다 더 구체적이고 명확하게 규명된다면, 서비스-러닝의 한 요인으로서 코디네이터를 명시하고 더욱 효과적으로 역할을 감당 할 수 있을 것이다.

\section{Notes}

This article was presented at the 2018 Annual Spring Conference of the Korean Association of Child Studies.

\section{Conflict of Interest}

No potential conflict of interest relevant to this article was reported.

\section{References}

\section{In English}

Alvarado, M. \& Gonzalez, P. A. (2012). Experiences in ServiceLearning among counselor education students. Paper presented at the 2012 Conference of the Southern Association of Counselor Education and Supervision, Savannah, GA.

Arnold, R., \& McMurtery, R. F. (2011). Integrating ServiceLearning into counselor education: Applications and implications. An Interdisciplinary Journal, 24(1), 59-74.

Association for Counselor Education and Supervision. (1990). Standards and procedures for school counselor training and certification. Counselor Education and Supervision, 29(4), 213-215.

Baggerly, J. (2006). Service-Learning with children affected by poverty: Facilitating multicultural competence in counseling education students. Journal of Multicultural
Counseling \& Development, 34(4), 244-255. doi:10.1002/ j.2161-1912.2006.tb00043.x

Baker, S. B., \& Daniels, T. G. (1989). Integrating research on the microcounseling program: A meta-analysis. Journal of Counseling Psychology, 36(2), 213-222. doi:10.1037//00220167.36.2.213

Barbee. P. W., Scherer, D., \& Combs, D. C. (2003). Prepracticum Service-Learning: Examining the relationship with counselor self-efficacy and anxiety. Counselor Education \& Supervision, 43(2), 108-119. doi:10.1002/j.1556-6978.2003.tb01835.x

Burnett, J. A., Hamel, D., \& Long, L. L. (2004). Service-Learning in graduate counselor education: Developing multicultural counseling competency. Journal of Multicultural Counseling \& Development, 32(3), 180-191. doi:10.1002/j.21611912.2004.tb00370.x

Havlik, S. A., Bialka, C., \& Schneider, K. (2016). Theory to practice: integrating service-learning into a pre-practicum introduction to school counseling course. The Journal of Counselor Preparation and Supervision, 8(2). 28-51. doi:10.7729/82.1168

Jacoby. B. (1996). Foundations and principles of Service-Learning. In Jacoby, B. (Ed,). Service-Learning in higher education: concepts and practices (pp. 1-25). San Francisco, CA: JosseyBass Publishers.

Knitzer, J. (1993). Children's mental health policy: Challenging the future. Journal of Emotional and Behavioral Disorders, 1(1), 8-16. doi:10.1177/106342669300100104

Melissa L. H., Jessica. M., \& Gretchen. G. P. (2017). Emotional and Behavioral problems of young children ( $2^{\text {nd }}$ ed.). New York: The Guilford Publications.

Moras, K., \& Strupp, H. H. (1982). Pretherapy interpersonal relations, patients' alliance and the outcome in brief therapy. Archives of General Psychiatry, 39(4), 405-409. doi:10.1001/ archpsyc.1982.04290040019003

Murray, C. E., Lampinen, A., \& Kelley-Soderholm, E. L. (2006). Teaching family systems theory through Service-Learning. Counselor Education and Supervision, 46(1), 44-58. doi:10.1002/j.1556-6978.2006.tb00011.x

Parker, J., \& Asher, S. R. (1987). Peer relations and later personal adjustment: Are low-accepted children at risk? Psychological Bulletin, 102(3), 357-389. doi:10.1037/00332909.102.3.357

Perkins, G., \& Brumfield. K. (2009). Service-Learning in counselor education programs: Combating truancy. In G. R. Walz, J. C. Bleuer, \& R. K. Yep (Eds.), Compelling counseling interventions; VISTAS 2009 (pp. 185-195). Alexandria, VA: American Counseling Association.

Ray, D. (2011). Advanced play therapy: Essential conditions, knowledge, and skills for child practice. New York: BrunnerRoutledge

Rønnestad, M. H., \& Skovholt, T. M. (2003). The journey of the 
counselor and therapist research findings and perspectives on professional development. Journal of Career Development, 30(1), 5-44. doi:10.1177/089484530303000102

Servaty-Seib, H. L., \& Parikh, S. J. T. (2014). Using ServiceLearning to integrate death education into counselor preparation. Death Studies, 38(3), 194-202. doi:10.1080/0 7481187.2012 .738774

Waters, E., Garber, J., Gornal, M., \& Vaughn, B. E. (1983). Q-sort correlates of social competence. Developmental Psychology, 19(4), 550-560. doi:10.1037//0012-1649.19.4.550e

\section{In Korean}

Ahn, H.-J. (2010). Examining conceptions of volunteering in early childhood education from diverse perspectives. Korean Journal of Human Ecology, 19(3), 471-485. doi:10.5934/ KJHE.2010.19.3.471

An, R. R. (2005). The relationship between children's individual variables, mothers' emotionality and the children's emotional development, social competence. (Doctoral dissertation). Retrieved from http://www.riss.kr./link?id=T10024327

An, R. R., \& Kim, H. J. (2008) The relationship between children's individual variables, mothers' emotionality and children's social competence. Family and Environment Research, 46(2). $1-12$

Bae, S. (2017). A preliminary study of effectiveness of a global (Cambodia) Service-Learning course at the university. Global Studies Education, 9(3), 3-39.

Chang, K.. (2010). The study of change of 'Educational Service' course through Service-Learning, The Journal of Korean Teacher Education, 27(3), 373-393.

Chi, S.-A., \& Kim. S.-H. (2015). The Structural Relationships among Young Children's Theory of Mind, Hot Executive Function, Cognitive Ability and Self-Esteem, Early Childhood Education Research \& Review, 19(4), 5-28

Choi, A., \&, Song, Y. (2015). A qualitative research on preservice teacher's experiences regarding the Service-Learning in inclusive education setting. The Journal of Developmental Disabilities, 19(1), 1-23.

Choi, J. (2011). The effects of elementary preservice teachers' mentoring experience for multicultural students as ServiceLearning. The Journal of Korean Teacher Education, 28(4), 237-263.

Chung, M. J., Jae, K. S., Lee, H. R., Shin, S., \& Park, J. (2016). Foundations of child counseling. Seoul: Hakjisa.

Han, I.-Y., Park, H.-W., \& Kim, J.-H. (2005). Implementation of Service-Learning for social work education. Korean Journal of Social Welfare, 57(3), 251-276.

Heo, K. H., \& Noh, J. N. (2012). Perceptions of korean early childhood special educators' use of strategies to address young children's challenging behaviors. Korean Journal of Early Childhood Special Education, 12(3), 285-304

Hong, S.-Y. (2015). The effects of maternal beliefs about children's emotions and reactions to preschooler's negative emotions on preschooler's internalizing problem behavior (Master's thesis). Retrieved from http://www.riss.kr/link?id=T13819196

Hwang, M. (2009). A study on the Service-Learning as a means of the participatory approach of law-related education, Journal of Law-Related Education, 4(2), 133-161.

Jee, S., Park, C., \& Lim, Y. (2005). Intern counselors' helpful experiences $\&$ regrets in the individual counseling supervision. The Korean Journal of Counseling and Psychotherapy, 17(1), 75-90.

Jeong, S., \& Han, Y. (2017). The use of a play therapy program at a child care center and the effects on children's daily stress, problem behaviors and adaptive behavior, Korean Journal of Play Therapy, 20(3), 219-234.

Kim, G., \& Jeong, N. (2004). Novice therapists' difficulty experienced in counseling session and coping process: a qualitative analysis. The Korean Journal of Counseling and Psychotherapy, 16(1), $1-20$.

Kim, J., \& Sung, J. (2014). The effects of mother's parenting behavior style on individual differences in preschooler's internalizing and externalizing behavior both at home and in preschool and teacher-child relationships. Korean Journal of Early Childhood Education, 34(6), 391-410.

Kim, K., \& Moon, S. (2000), Educational need assessment of counseling trainees in supervision. The Korean Journal of Counseling and Psychotherapy, 12(1), 1-18.

Kim. M. (2009). The development of the scale about novice therapists' difficulty experienced in counseling. The Korea Journal of Youth Counseling, 17(2), 21-37.

Kim, S. (1997). A study of the concepts and principles of ServiceLearning. Ewha Journal of Social Sciences, 1, 41-61.

Kim, Y. (2007). Determinants of teachers' quality of instruction: Focusing on children's problem behaviors and protective factors of quality of instruction. Korean Journal of Early Childhood Education, 27(6), 213-238

Kim, Z., Han, N., \& Lee, D. (2009). The concept map of novice and expert counselors' perceived difficulties and overcoming strategies. Korea Journal of Counseling, 10(2), 769-792.

Koo, H. (2009). A structural equation modeling analysis of the influence of language, cognitive, and social and emotional development on the children with aggressive behavior at multi-cultural families in agricultural \& fishing areas. Korean Journal of Early Childhood Special Education, 9(3), $1-21$.

Korea Research Institute for Vocational Education \& Training. (2018). Private qualification information service [Web page]. Retrieved July 1, from https://www.pqi.or.kr

Kwak, Y.-J., \& Ahn, H. (2017). A study on the current status of 
Service-Learning in art education: survey evidence from arts high schools in Seoul and Gyeonggi province. Art Education Review, 63, 21-42

Lee, E. H., Lee, M. L., \& Park, S. Y. (2006). Specimen Selection, The comprehension of research method for children[아동 연구 방법의 이해](pp. 135-152) Seoul: Hakjisa.

Lee, J. (2012). Testing the relationship between child and mother's temperaments and child's behavioral problems, The Korean Journal of Clinical Psychology, 31(3), 801-822.

Lee, J. H., \& Chung, K. S. (2008). The effects of a teachers' empathetic attitude program based on Kinder Therapy on improving social relationships of maladjusted young children. Korean Journal of Early Childhood Education, 28(5), 295-318.

Lee, M. (2013). An analysis on the effect of the group education for case conceptualization. Journal of Arts Psychotherapy, 9(3), 113-131.

Lee, M., Kim, U., Kim, O., Shim, M., Kang, J., Yoo, H., .. . Yoon, J. Y. (2013). Parent Education Guide for Infant Problem Behavioral Guidance, Retrieved from NKIS website: https:// www.nkis.re.kr

Lee, M., \& Yeon, M. (2004). A study on development of case conceptualization training program. The Korea Journal of Youth Counseling, 12(1), 143-155.

Lee, Y.-R., \& Kim, N.-Y. (2006). A study on the Service-Learning module development of social welfare subject: Focused on volunteer management. Korean Journal of Clinical Social Work, 3(1), 173-200.

Lee, Y. S. (2014). Problematic behavior according to the children's resilience type, Journal of Early Childhood Education \& Educare Welfare, 18(4), 61-91.

Lee, Y. (2018). Case study on childcare center based play therapy for child who had maladapted behaviors. The Study of Child-Family Therapy, 16(0), 41-57.

Park, J.-U. (2015). A study on needs for Korean teaching practice as service-learning: Focused on service-learning at Korea immigration and integration program (Master's thesis). Retrieved from http://www.riss.kr/link?id=T13732790

Park, W. Y. \& An, R. R. (2006). A study of the relationships between social competence and emotional regulation strategies used by 3, 4, and 5-year-old children. Korean Journal of Early Childhood Education, 26(4), 351-369.
Seo, E.-H. (2009). The effect of Service-Learning on teacher efficacy and academic adjustment for female prospective teachers. The Journal of Korean Teacher Education, 26(3), $1-18$.

Shim, H. (1998). Assessment of the developmental levels of korean counselors (Doctoral dissertation). Retrieved from http:// www.riss.kr/link?id=T4470034

Shin, E. S., Kwon, M. K., \& Jeong, H. B. (2010). The relationships between social skills, peer play interactions and social play behaviors. Journal of Future Early Childhood Education, 17(4), 183-209

Shin, S. M. (2013). A study for Service-Learning program relative to music college curriculum. Korean Journal of Arts Education, 11(1), 85-107.

Son, S., Na, K.-E., Moon, J., \& Seo, Y.-J. (2011). Qualitative analysis of Service-Learning experiences of pre-service teachers. The Korean Journal of Educational Methodology Studies, 23(3), 529-553.

Wang, H., \& Han, S. (2011). Effects of mother's neuroticism, perfectionism and psychological control on young children's onternalizing problem behavior. Journal of Human Ecology, 17(1), 41-53.

Won, M.-S., \& Park, H.-S. (2008). Effects of Service-Learning experience embedded in course work: An experimental study. Journal of School Social Work, 15, 57-76.

Yang, S. Y., \& Han, Y. J. (2017). The effects of a child-centered play therapy internship program for novice play therapists on the professional competence of play therapists. Journal of Korean Home Management Association, 35(1), 83-105. doi:10.7466/JKHMA.2017.35.1.83

\section{ORCID}

You Jin Han http://orcid.org/0000-0001-6406-0852

Sun Hee Chung https://orcid.org/0000-0002-7027-8695

Received April 30, 2018

Revision received June 23, 2018

Accepted August 5, 2018 